\title{
O conglomerado de Mont Serrat e suas relações com o alto e a falha de Salvador, Bahia
}

\author{
Johildo Salomão Figueiredo Barbosa ${ }^{1}$, José Maria Landim Dominguez ${ }^{2}$, \\ Luiz César Corrêa-Gomes ${ }^{3}$ \& Moacyr Moura Marinho ${ }^{4}$
}

\begin{abstract}
Resumo Durante o mapeamento geológico da cidade Salvador, conglomerados foram estudados em detalhe na Ponta de Mont Serrat. Esta se localiza próxima a escarpa da Falha de Salvador que separa o Alto de Salvador situado a leste, da Bacia do Recôncavo localizada a leste. Estes conglomerados da Formação Salvador fornecem boas indicações dos tipos das rochas fonte e dos ambientes de sedimentação onde eles foram depositados. No Alto de Salvador foram identificadas rochas orto e paraderivadas intensamente deformadas e metamorfisadas na fácies granulito e anfibolito, alem de diques máficos e corpos de sieno-granitos posteriores. $\mathrm{O}$ conglomerado apresenta-se mal classificado e pouco alterado, sendo formado basicamente por clastos de granulitos e de gnaisses da fácies anfibolito. As estruturas sedimentares e a geometria dos canais identificados nos afloramentos de conglomerado indicam a atuação de vários processos incluindo tração, fluxos de grãos e fluxos de detritos, sugerindo que a deposição ocorreu em leques deltaicos que adentraram o lago tectônico da Bacia do Recôncavo. Estes fluxos se dirigiram predominantemente para SW, segundo provavelmente a direção principal de basculamento da bacia. O caráter sub-angular e a composição dos clastos levam a concluir que estes foram oriundos de áreas fontes próximas, do Alto de Salvador. Os eixos dos clastos no afloramento estudado possuem orientações dominantemente perpendiculares à Falha de Salvador, indicando um transporte também para SW, uma vez que, quando clastos são transportados por tração ao longo do fundo, o eixo maior dos mesmos tende a se orientar perpendicularmente ao sentido dominante das correntes. Como os clastos são constituídos de rochas das fácies granulito e anfibolito a crosta continental paleoproterozoica, na época da formação da bacia, estava ainda quase completa, tendo sido erodida apenas as rochas da fácies xisto-verde. A ocorrência de clastos de calcário sugere que a Formação Estância do neoproterozoico, possivelmente existia nas proximidades da Salvador na época da formação da Bacia do Recôncavo.
\end{abstract}

Palavras-Chave: Conglomerados, origem, ambiente de sedimentação, Mont Serrat, Salvador, Bahia, Brasil.

\begin{abstract}
The conglomerate of Mont Serrat and its relationships with the Salvador high and the Salvador fault, Bahia. During the geological mapping of the Salvador city the conglomerates outcropping at Mont Serrat were studied. This outcrop is located near the escarpment of the Salvador fault, which marks the boundary between the Salvador high and the Recôncavo basin. These conglomerates belong to the Salvador formation, and they provide useful information concerning the major rock types at the source areas and the deposicional environments. The Salvador high is comprised of ortho and para-derived rocks intensely deformed and metamorphosed in the granulite and amphibolite facies, together with mafic dikes and sienogranites emplaced in a more recent time. The sedimentary structures and channel geometry indicate the action of a variety of depositional and transport processes including traction, grain flows and debris flows. Sediments accumulated in fan deltas prograding into the tectonic lake of the Recôncavo basin from the Salvador fault. The dominant sediment transport direction was towards southwest, following the dominant dip of the Recôncavo basin depocenter. Conglomerate clasts are dominantly subangular and their composition indicates a nearby source area at the Salvador high. Clast's long axis are oriented dominantly perpendicular to the Salvador fault, indicating a SW transport because, under a tractive regime, clast's long axis are commonly oriented perpendicular to flow direction. Clasts are dominantly composed of high-grade metamorphic rocks of the amphibolite and granulite facies belonging to the paleoproterozoic continental crust. At the time the conglomerates accumulated, the portion of the continental crust composed of green-schist metamorphic facies rocks had already been eroded. The occasional presence of limestone pebbles indicates that remnants of the Estancia Formation of Neoproterozoic age, possibly outcropped somewhere in the Salvador high, by the time subsidence at the Reconcavo basin was active.
\end{abstract}

Keywords: conglomerates, sedimentary environments, Mont Serrat, Salvador, Bahia, Brazil.

1 - Instituto de Geociências - Universidade Federal da Bahia. Salvador, Bahia, Brasil. E-mail: johildo@cppg.ufba.br

2 - Instituto de Geociências - Universidade Federal da Bahia. Salvador, Bahia, Brasil.E-mail: landim@ufba.br

3 - Centro Federal de Educação Tecnológica da Bahia. Depto. de Ciências Aplicadas, Salvador, Bahia, Brasil. E-mail: gomes@cefetba.br

4 - Instituto de Geociências - Universidade Federal da Bahia. Salvador, Bahia, Brasil. E-mail:cbpmdt@cbpm.com.br 
INTRODUÇÃO Durante o processo de formação de bacias do tipo rifte é comum a acumulação de rochas conglomeráticas associadas às falhas de borda. A Bacia do Recôncavo é um desses casos, ocorrendo na cidade de Salvador, afloramentos desses litotipos os quais contêm clastos de tamanho médio acima de $5 \mathrm{~cm}$, permitindo o seu estudo detalhado e fornecendo boas indicações dos tipos das rochas-fonte e dos ambientes de sedimentação onde estes conglomerados foram depositados.

Durante o mapeamento geológico da Cidade Salvador (Barbosa et al, em preparação) conglomerados foram estudados em detalhe nas proximidades da escarpa da Falha de Salvador, na Ponta de Mont-Serrat, no bairro de Itapagipe, na parte baixa da cidade. Estas rochas conglomeráticas fazem parte da denominada Formação Salvador que ocorre na borda leste das bacias do Recôncavo e Tucano Sul/Central e, borda noroeste das bacias de Jatobá e Tucano Norte (Fig. 1). Conforme Caixeta et al. (1994), esta Formação é o resultado da deposição em leques aluviais sintectônicos que marcaram a atuação das falhas de borda da fase rifte dessas bacias.

O estudo detalhado da composição mineralógica e das orientações dos eixos maiores dos clastos deste conglomerado, complementado pelas informações sobre as estruturas sedimentares permitiu reconstruir os processos de deposição e a relação destes conglomerados com a Falha de Salvador, que limita a leste a Bacia do Recôncavo.

GEOLOGIA REGIONAL As rochas que ocorrem na cidade de Salvador e arredores são aquelas da bacia do Recôncavo e os metamorfitos do Alto de Salvador, ambas parcialmente recobertas por sedimentos da Formação Barreiras (Fig.1).

$\mathrm{Na}$ Bacia do Recôncavo são identificadas rochas do Grupo Ilhas e das formações São Sebastião e Salvador. O Grupo Ilhas (Kis) (Caixeta et al. 1994), aflora a noroeste de Salvador, ocupando boa parte do contorno da Baia de Todos os Santos, sendo constituído por folhelhos verde oliva, arenitos, siltitos e calcários (Fig. 1). A Formação São Sebastião (Kss) (Viana et al., 1971), que faz parte do Grupo Massacará, situa-se mais ao norte de Salvador. Ela é constituída por arenitos grossos, amarelos avermelhados com intercalações de argilas silticas depositadas por sistemas fluviais, sendo composta pelos membros Paciência (arenito fino a grosso e folhelho preto), Passagem dos Teixeiras (arenito fino a médio e folhelho cinza) e Rio Joanes (arenito fino e argila avermelhada). A Formação Salvador aflora na borda da Bacia do Recôncavo e apresenta corpos de conglomerados com geometria em cunha que afinam tanto em espessura quanto em granulometria para o centro da bacia. A Formação Salvador é interpretada como resultado da deposição em ambiente de leques deltáicos (Medeiros \& Pontes 1981, Magnavita et al., 1998). Segundo Miura (1967) foram identificados três tipos de conglomerados, com base nas litologias predominantes nos clastos: (i) conglomerados com clastos de calcário; (ii) conglomerados com clastos de arenito e, (iii) conglomerados com clastos de rochas metamórficas. O corpo de conglomerado de Mont Serrat que aparece na parte baixa da Cidade de Salvador, se enquadra no ultimo tipo. Ele é o maior e mais bem exposto dos diversos afloramentos de conglomerado que ocorrem no bloco baixo da Falha de Salvador, a qual separa os sedimentos da Bacia do Recôncavo das rochas arquenas-paleoproterozoicas que ocorrem no Alto de Salvador (Fig. 1).

No Alto de Salvador foram identificadas rochas orto e paraderivadas intensamente deformadas e metamorfisadas na fácies granulito e anfibolito alem de diques máficos e corpos de sienogranitos posteriores

Entre as rochas ortoderivadas predominam metatonalitos e charnoenderbitos, ambos leuco a mesocráticos e geralmente com textura xenoblástica, com o tamanho dos grãos variando entre 0,5 e $3-5 \mathrm{~mm}$. Os metatonalitos são formados de plagioclásio antipertítico, quartzo, ortopiroxênio e clinopiroxênio tendo os opacos, apatita e zircão como minerais acessórios, além da hornblenda e biotita que são secundários e ocorrem também em pequenas quantidades. Os charnoenderbitos apresentam plagioclásio antipertítico, quartzo e mesopertita ou microclina pertítica, aparecendo o hiperstênio em menor proporção, além dos acessórios opacos, apatita e zircão. Nos charnoenderbitos a biotita é secundária e aparece em pequena proporção. Metagabros (plagioclásio, ortopiroxênio, clinopiroxenio e hornblenda marrom) e metapiroxenitos (ortopiroxênio, clinopiroxênio e plagioclásio) ocorrem como enclaves dentro das rochas ortoderivadas anteriores.

No que diz respeito às rochas metamórficas paraderivadas elas ocorrem em faixas de espessuras variadas, inclusas tectonicamente nos granulitos ortoderivados. Nessas faixas ocorrem granulitos alumino-magnesianos, metabasitos e quartzitos, sob a forma de bandas métricas intercaladas (Fujimori \& Allard 1966, Fujimori 1968). Os granulitos alumino-magnesianos exibem granulação fina a média, textura em geral granoblástica e às vezes apresentando porfiroblastos. Elas são formadas por quartzo, ortoclásio, plagioclásio, granada, silimanita e cordierita como minerais principais e espinélio, rutilo, biotita e coríndon além de rara safirina. Opacos, zircão e monazita formam os minerais acessórios (Fujimori 1968). Ortopiroxênio e a safirina as vezes são identificadas nessas rochas paraderivadas (Fujimori \& Allard 1966). Os metabasitos exibem cor verde escura, são foliados com textura fina, granoblástica sendo os principais minerais metamórficos o plagioclásio, o clinopiroxênio, o ortopiroxênio, a hornblenda marrom e o quartzo. Opacos e apatitas são os acessórios ocorrendo ainda biotitas e hornblendas verdes, secundárias. Os quartzitos são cinza claros, com textura granular, exibindo foliação penetrativa e sendo formados de quartzo, plagioclásio sericitizado, opacos e biotita secundária.

Cortando essas rochas metamórficas ocorrem, pelo menos, duas gerações de diques máficos de coloração preta e textura fina. São predominantemente tabu- 


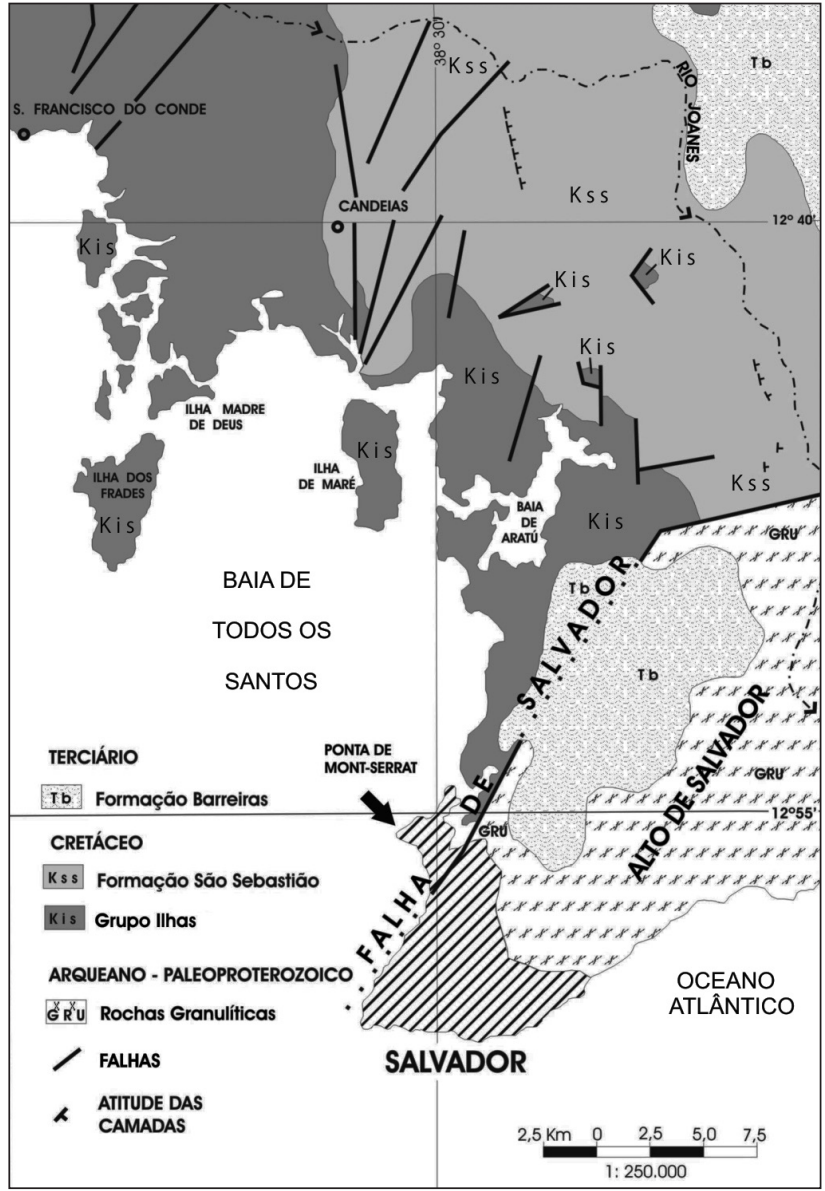

Figura 1-Mapa geológico simplificado de Salvador e arredores. PETROBRÁS (1965).

lares, verticais mostrando espessuras bastante dispares, desde $1 \mathrm{~cm}$ a $50 \mathrm{~m}$ com direções variadas. Ocorrem tanto na orla marítima de Salvador como no seu interior (Fujimori \& Allard 1966, Fujimori 1968, Tanner de Oliveira \& Conceição 1982, Mestrinho et al. 1982, 1988, Moraes Brito 1992, Corrêa-Gomes 1992, CorreaGomes et al. 1996). Possuem cristais maiores de plagioclásio, augita além de pigeonita e olivina subordinadas sendo que como cristais menores foram identificados plagioclásio, augita, opacos e pigeonita (Moraes Brito 1992). Hornblenda, biotita e clorita foram fases formadas no final da cristalização a partir da alteração dos piroxênios. Corpos de sienogranitos de formato tabular também cortam as rochas metamorficas anteriores estando, não raramente, associados aos diques máficos da geração mais antiga (Celino et al. 1984, Moraes Brito 1992). Estes corpos granitóides são constituídos basicamente de quartzo, microclina e biotita, aparecendo como acessórios, o plagioclásio, os opacos e o zircão.

Além dessas litologias são identificados também, sobretudo nos arredores de Salvador, os sedimentos terciários da Formação Barreiras. Estes repousam em discordância angular sobre as rochas sedimentares cretáceas e sobre as rochas do embasamento cristalino sendo constituídos basicamente de areias de granulação grossa e de cores variegadas, argilas e cascalhos.
GEOLOGIA LOCAL E MÉTODOS DE TRABALHO A área de Mont Serrat é formada essencialmente de rochas conglomeráticas da Formação Salvador que constituem corpos irregulares e dispersos dentro do Grupo Ilhas.

No estudo desses litotipos confeccionou-se um mapa topográfico (Fig. 2) e um mapa geológico (Fig. 3) dos afloramentos os quais ocorrem ao nível das praias, tanto a sul (Fig. 4) quanto a norte da Igreja de Mont Serrat (Fig. 1). Estes mapas foram realizados com auxilio de prancheta e alidade, na escala 1:200. Foram feitas várias seções geológicas paralelas, dispostas ao longo das dimensões maiores dos afloramentos e espaçadas de 3,5 metros uma da outra (Fig. 5). Sobre as seções ou linhas-base foram estudados em detalhe os clastos situados a cada $20 \mathrm{~cm}$. Nesses pontos foram extraídos dos clastos os seguintes dados: tipo litológico e grau de alteração superficial; arredondamento; esfericidade; dimensões (eixo maior, menor e intermediário) e atitude (orientação e mergulho) dos seus eixos maiores (Tab. $1)$.

Nos trabalhos de campo verificou-se que na parte norte do afloramento o conglomerado é mais regular sem variações litológicas. Entretanto, na parte sul, ocorrem lentes intercaladas de arenitos e de folhelhos (Figs. 3,4). O arenito é amarelado, de granulação fina a média, mostrando em alguns locais vestígios de estratificação cruzada e, da maneira como se apresentam em afloramento, parece ter sido contemporâneo à deposição dos clastos. As camadas de folhelho, com mergulhos suaves sempre para nordeste, possuem coloração verde acinzentada estando sempre afetadas por microdobramentos em função de deslizamento do material sedimentar durante a deposição. As relações entre o conglomerado e as lentes de arenito e camadas de folhelho estão mostradas nas seções geológicas da figura 3. De modo geral estes pacotes sedimentares se encontram orientados segundo N165o com mergulhos em torno de 5o a 10o NE.

O conglomerado apresenta-se mal classificado e pouco alterado, sendo formado por clastos de granulitos $(52 \%)$, de gnaisses da fácies anfibolito $(22 \%)$, de sieno-granitos (9\%), de meta-gabros $(8 \%)$, de arenitos (6\%) e de quartzo leitoso (3\%) (Fig. 4). Os clastos apresentam dimensões que variam de poucos centímetros até quase um metro, sendo os maiores constituídos de granulito. Vale destacar que foram encontrados dois clastos de calcário (calcita, quartzo e opacos) e mais um de kinzigito (quartzo, ortoclásio, plagioclásio, granada, silimanita, espinélio), ambos de cor cinza, maciços e pouco alterados. Destes não constam os dados porque situaram-se entre as linhas base de coleta de dados (Fig $5)$.

ESTUDO PETROGRÁFICO DOS CLASTOS Em amostras representativas de cada um dos grupos de clastos encontrados em Mont Serrat se procedeu a análise petrográfica. No grupo dos granulitos foram identificados metatonalitos (plagioclásio, quartzo, ortopiroxênio, clinopiroxênio, biotita) e charnoenderbitos (plagioclá- 


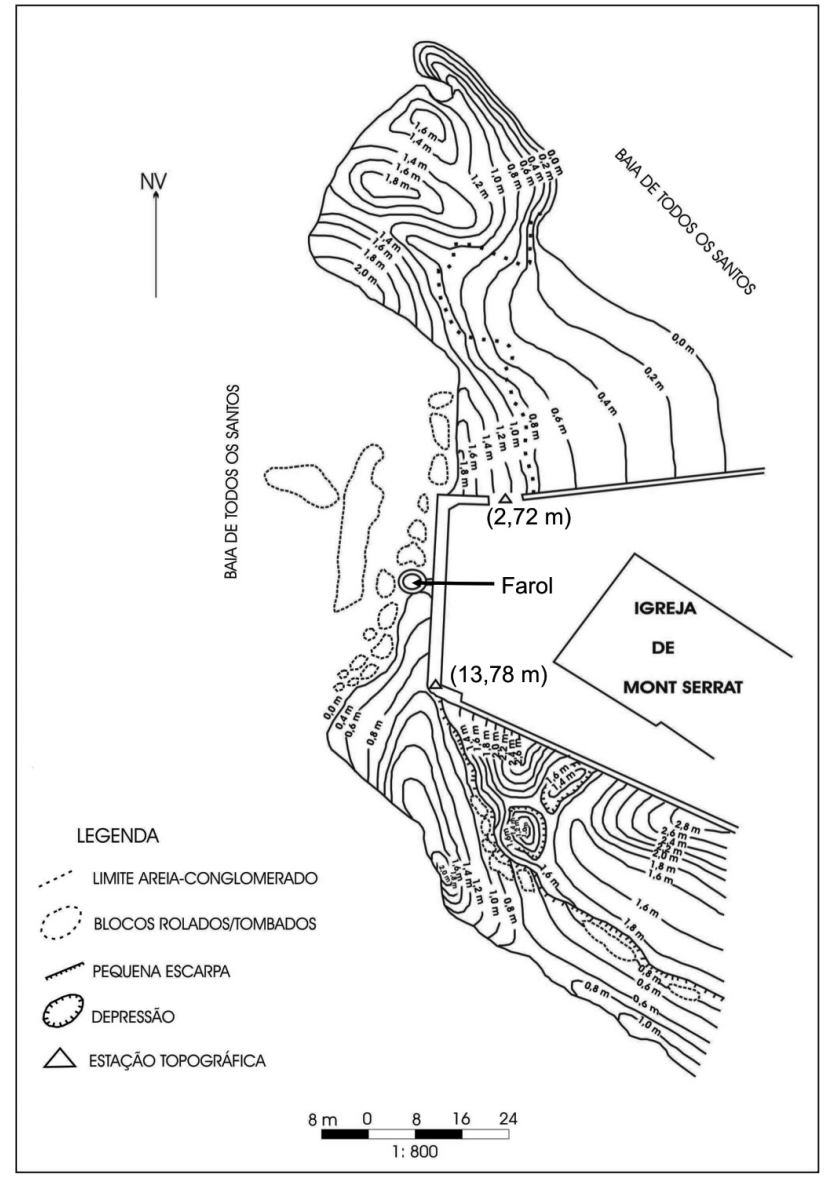

Figura 2 - Mapa topográfico do afloramento de conglomerado de Mont Serrat. A curva de 0 metro corresponde ao nível de baixa mar, de acordo com a Tabela de Marés da Marinha do Brasil.

sio antipertítico, quartzo, ortoclásio, hiperstênio além de opacos, apatita e zircão). Os clastos de sienogranitos exibem microscopicamente uma mineralogia composta de quartzo, microclina e biotita aparecendo como acessórios, o plagioclásio, os opacos e o zircão. Os clastos de metagabros são formados de plagioclásio, ortopiroxênio, clinopiroxenio e hornblenda marrom, possuindo também uma boa quantidade de opacos. Os clastos de arenito possuem uma mineralogia composta de quartzo (70\%), calcita como cimento (20\%), restando como acessórios a clorita $(2 \%)$, a albita $(5 \%)$ e a microclina (3\%). Os clastos de quartzo são os menos numerosos e compostos de quartzo (97\%) e opacos (3\%). Deve ser destacado que além dessas rochas foram encontrados entre os clastos mais de $20 \%$ de gnaisses da fácies anfibolito sendo em geral compostos de $50 \%$ de quartzo, $30 \%$ de microclina, $10 \%$ de plagioclásio e cerca de $10 \%$ de biotita, sem considerar os minerais acessórios.

\section{COMPOSIÇÃO E ORIENTAÇÃO DOS CLAS-}

TOS Os dados obtidos sobre orientação e composição dos clastos estão apresentados na tabela 1 .

Do ponto de vista da composição verificou-se que há uma predominância em ordem decrescente de

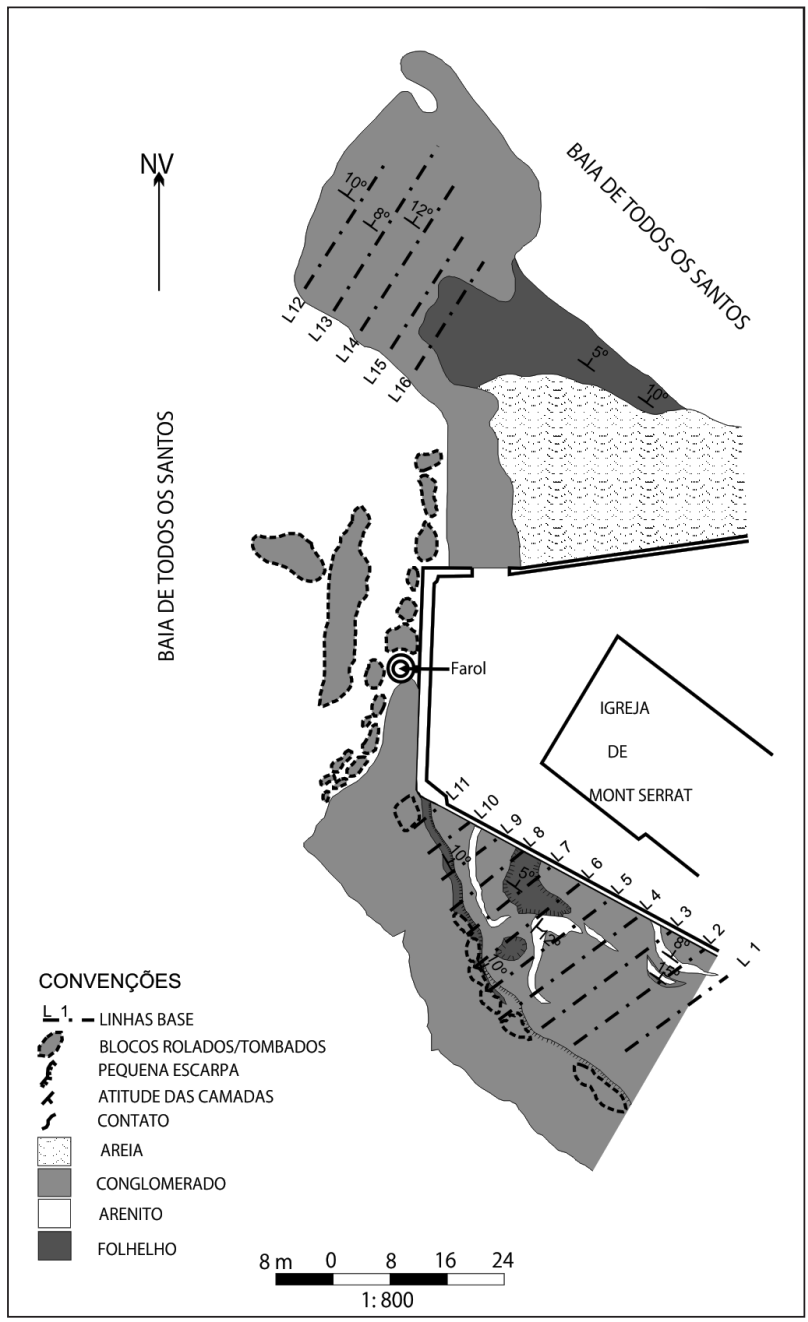

Figura 3 - Mapa geológico do afloramento de conglomerado de Mont Serrat realizado com prancheta e alidade.

clastos de granulitos, gnaisses, sienogranitos, metagabros, arenitos e quartzo leitoso (Fig. 6A). Com relação ao arredondamento dos clastos, observou-se que ocorre uma proporcionalidade quase igual entre os clastos angulares, sub-angulares e sub-arredondados, sendo mínima a quantidade encontrada de clastos arredondados (Fig. 6B). Quanto a esfericidade, as três dimensões dos clastos medidas em afloramento foram utilizadas na equação 1:

$$
(\mathrm{L}+\mathrm{I}) / 2 \mathrm{E}
$$

onde L é igual ao comprimento do eixo maior, I igual ao eixo intermediário e $\mathrm{E}$ igual ao eixo menor (sendo portanto $\mathrm{L}>\mathrm{I}>\mathrm{E}$ ). Os resultados obtidos foram agrupados nas seguintes classes de esfericidade: de 1,00-1,50 muito alta esfericidade (MAE); 1,50 - 2,0 alta esfericidade (AE); 2,00 - 2,50 média esfericidade (ME); 2,50 - 3,00 baixa esfericidade (BE) e $>3,00$ muito baixa esfericidade (MBE). Verificou-se que a classe alta esfericidade predomina ligeiramente sobre as demais, embora note-se também uma quase igualdade na percentagem de clastos com muito alta esfericidade e mé- 

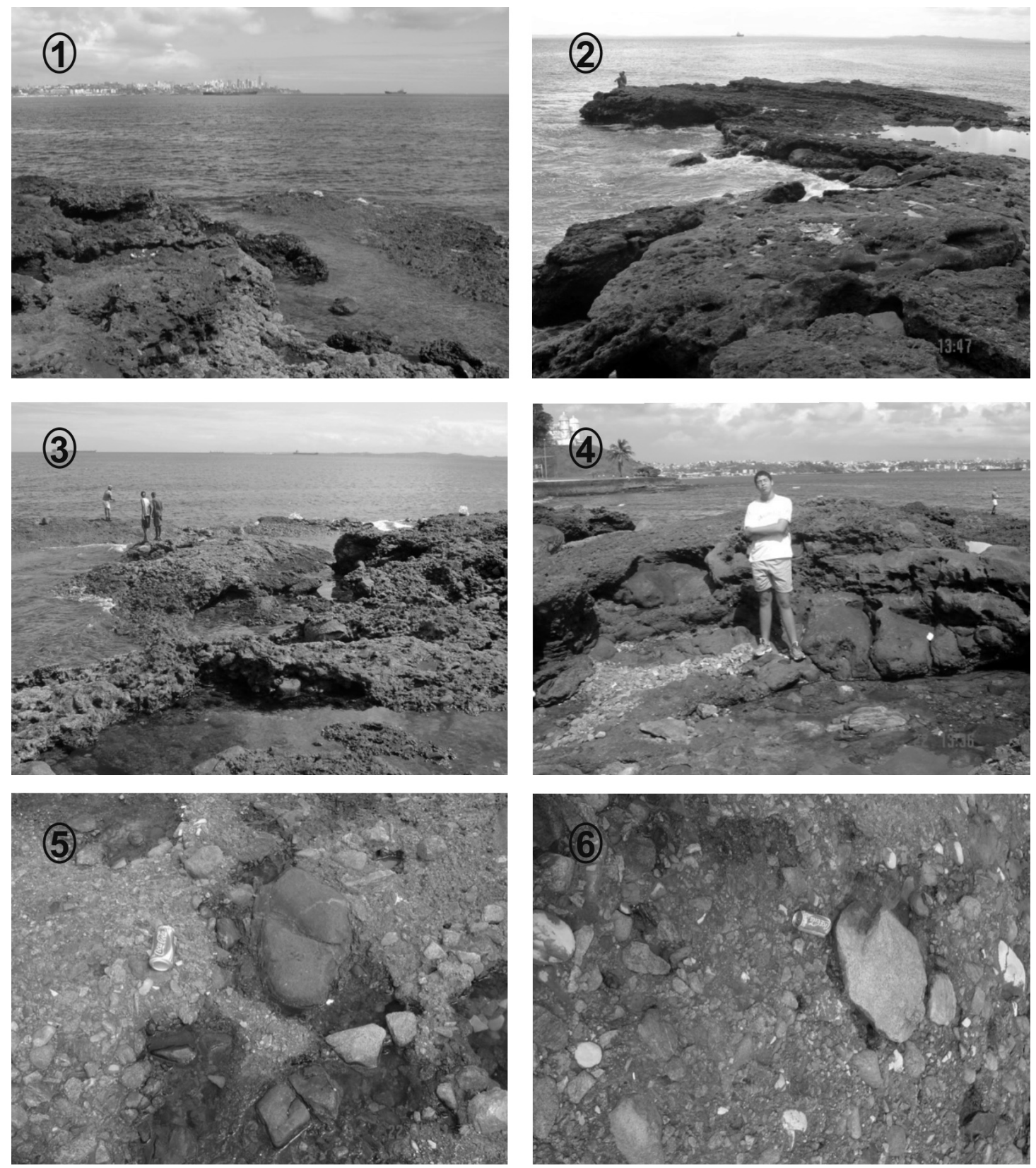

Figura 4 - Fotografias de campo das feições macroscópicas do conglomerado de Mont Serrat, Salvador: (1) Visão geral do afloramento de conglomerado de Mont Serrat vendo-se Salvador ao fundo, (2) Visão geral do afloramento de conglomerado de Mont Serrat mostrando o baixo mergulho das camadas em direção ao mar, (3) Afloramento do conglomerado mostrando a heterogeneidade nos tamanhos dos clastos, (4) Lente de arenito intercalada entre os clastos de conglomerado, (5) Visão da diversidade de tamanhos e tipos de litologias dos clastos: em destaque clasto de dique máfico proveniente do Alto de Salvador, e (6) Afloramento mostrando clastos menores de granulitos e maiores de sienogranitos provenientes do Alto de Salvador.

dia esfericidade. Clastos com baixa e muito baixa esfericidade são os de menor proporção encontrada (Fig. 6C). Com relação à alteração dos clastos notou-se que é mínima a quantidade daqueles alterados (A) ou muito alterados (MA) e a grande maioria encontra-se pouco alterada (PA) ou sem alteração (NA).

As 290 orientações de eixos maiores dos clastos investigados foram plotadas em rede estereográfica de igual área (hemisfério inferior) das quais foram obtidas linhas de isodensidade de ocorrência e assim produzi- das rosáceas de direção de caimento (plunge-direction) com pétalas em intervalos de $10 \mathrm{o}$ em 10o (Fig.7). As linhas correspondentes aos eixos dos clastos foram comparadas com o plano da Falha de Salvador, (FS) de modo a evidenciar relações espaciais entre a falha e as orientações dos mesmos. Na figura 7A pode ser notado que os eixos maiores caem predominantemente entre os quadrantes NE e SE, enquanto que o plano da FS (obtido a partir de seções sísmicas) apresenta direção N30o e mergulha cerca de 70o para NW. Quando são 


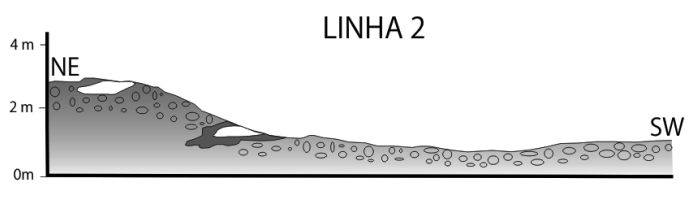

LINHA 4

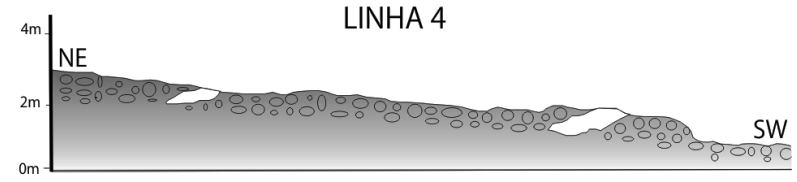

LINHA 5

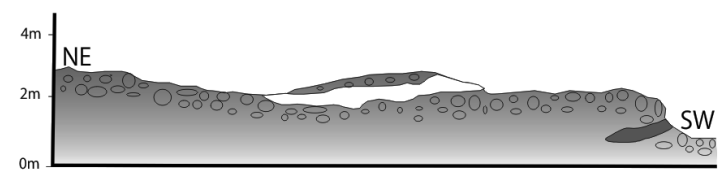

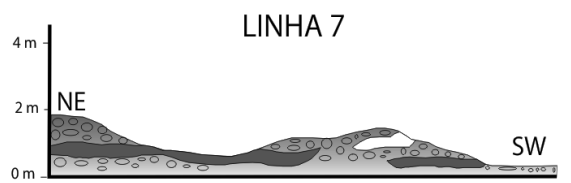

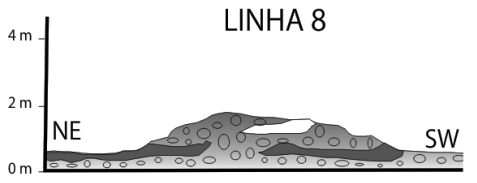

LINHA 13

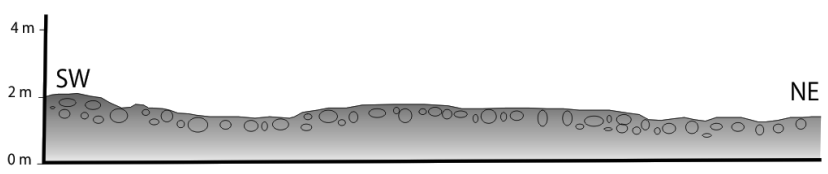

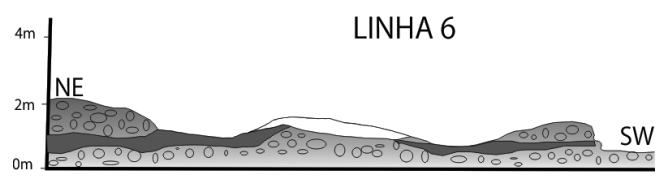

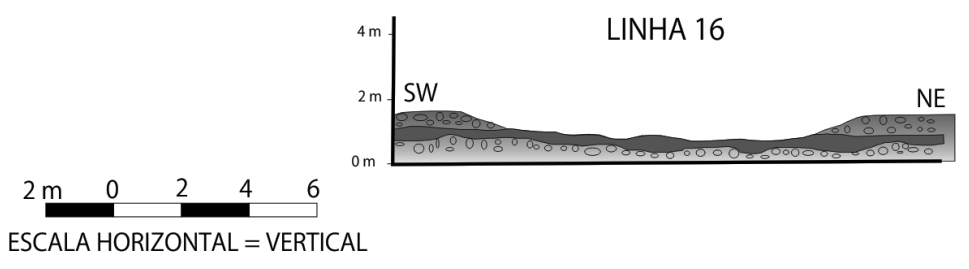

$\because 0^{\circ}$ CONGLOMERADO

FOLHELHO

ARENITO

Figura 5 - Seções geológicas sobre algumas linhas base selecionadas no afloramento de conglomerado de Mont Serrat.

geradas curvas de isodensidade a partir dos dados anteriores (Fig. 7B) duas concentrações de linhas aparecem nitidamente, sendo praticamente ortogonais entre si: uma próxima a N128o e outra próxima a N35o, essa última praticamente paralela ao strike da FS. A orientação dos eixos maiores dos clastos do conglomerado é dominantemente paralela a sub-paralela ao strike da $\mathrm{FS}$, e, secundariamente ortogonal a sub-ortogonal à FS (Fig. 7C).

DISCUSSÃO E CONCLUSÕES No local estudado não existem exposições que permitam observar perfeitamente a geometria tridimensional dos corpos de conglomerado. Entretanto, a aproximadamente 800 metros a sul, em outro afloramento da Formação Salvador, pode-se constatar que estes conglomerados ocorrem preenchendo canais (1 - 2 metros de largura) orientados sub-paralelamente à Falha de Salvador. O material que preencheu estes canais é capeado por camadas de arenito médio, maciços, que apresentam contato gradacional com os corpos conglomeráticos. Vistos em seção longitudinal, vários destes canais apresentam estratificações cruzadas de grande porte. Em alguns dos estratos frontais encontram-se os clastos de maior tamanho. Alguns canais são preenchidos predominantemente por areia e são cortados por canais menores preenchidos por cascalho.
Liquefação e fluidização são comuns nas camadas de areia. Tanto as estratificações cruzadas quanto o imbricamento dos clastos são também orientados subparalelamente à Falha de Salvador com fluxos dominantemente para SW.

As estruturas sedimentares e a geometria dos canais indicam a atuação de vários processos incluindo tração, fluxos de grãos e fluxos de detritos, sugerindo que a deposição ocorreu em leques deltaicos que adentraram o lago tectônico da Bacia do Recôncavo, oriundos da Falha de Salvador, conforme já apontado anteriormente por Medeiros \& Pontes (1981) e Magnavita et al., (1998). Estes fluxos, pelo menos no trecho estudado, se dirigiram predominantemente também para SW, seguindo provavelmente a direção principal de basculamento da bacia. Esta interpretação é suportada pelas medidas dos eixos dos clastos cuja orientação dos eixos maiores é dominantemente perpendicular à Falha de Salvador, indicando um transporte preferencialmente para SW, uma vez que, quando clastos são transportados por tração ao longo do fundo, o eixo maior dos mesmos tende a se orientar perpendicularmente ao sentido dominante das correntes. Desse modo é possível explicar a grande concentração de orientações dos eixos maiores dos clastos tanto ortogonalmente quanto sub-ortogonalmente à Falha de Salvador.

O caráter sub-angular dos clastos é sugestivo 
Tabela 1 - Exemplo de tabela com os dados geométricos dos clastos do conglomerado obtidos de 20 em $20 \mathrm{~cm}$ sobre as linhas base postadas sobre as dimensões maiores do afloramento (partes norte e sul). Obs. Aos interessados, o autor sênior (JSFB) pode disponibilizar todo o conjunto de dados geométricos coletados sobre os seixos do conglomerado de Mont Serrat através de contato via e-mail.

\begin{tabular}{|c|c|c|c|c|c|c|c|c|c|c|}
\hline \multicolumn{11}{|c|}{ LINHA n 1} \\
\hline \multirow{3}{*}{$\begin{array}{l}\stackrel{0}{0} \\
\stackrel{0}{0} \\
0\end{array}$} & \multirow{3}{*}{ Rocha } & \multirow{3}{*}{ 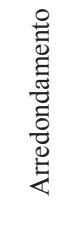 } & \multirow{3}{*}{ 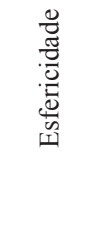 } & \multicolumn{3}{|c|}{$\begin{array}{l}\text { Dimensões dos clastos } \\
(\mathrm{cm})\end{array}$} & \multirow{3}{*}{$\begin{array}{l}(\mathrm{L}+1) / 2 \mathrm{E} \\
\mathrm{E}<=\mathrm{l}<=\mathrm{L}\end{array}$} & \multicolumn{2}{|c|}{ Atitude dos clastos } & \multirow{2}{*}{$\begin{array}{c}\begin{array}{c}\text { Alteração dos } \\
\text { clastos }\end{array} \\
\text { M.A. - A. }\end{array}$} \\
\hline & & & & \multirow{2}{*}{$\mathrm{L}$} & \multirow{2}{*}{1} & \multirow{2}{*}{$\mathrm{E}$} & & \multirow{2}{*}{ Direção } & & \\
\hline & & & & & & & & & INerguino & P.A. - N. A. \\
\hline 1 & gnaisse & A & MAE & 4 & 3 & 3 & 1,16 & N115 & 10SE & M.A. \\
\hline 2 & gnaisse & $\mathrm{A}$ & MAE & 3 & 3 & 2 & 1,50 & N60 & $60 \mathrm{NE}$ & A. \\
\hline 3 & matriz & & & & & & & & & \\
\hline 4 & gnaisse & SA & $\mathrm{AE}$ & 40 & 38 & 20 & 1,95 & N100 & 10SE & A. \\
\hline 5 & gnaisse & SAn & ME & 6 & 4 & 2 & 2,50 & N145 & $15 \mathrm{SE}$ & A. \\
\hline 6 & gnaisse & SAn & $\mathrm{ME}$ & 8 & 5 & 3 & 2,16 & $\mathrm{~N} 150$ & 20SE & N.A. \\
\hline 7 & quartzo & An & $\mathrm{AE}$ & 12 & 7 & 6 & 1,58 & N90 & $40 \mathrm{E}$ & N.A. \\
\hline 8 & matriz & & & & & & & & & \\
\hline 9 & quartzo & An & $\mathrm{AE}$ & 10 & 5 & 4 & 1,87 & - & - & N.A. \\
\hline 10 & gnaisse & SAn & $\mathrm{AE}$ & 8 & 5 & 4 & 1,62 & N100 & 80SE & A. \\
\hline 11 & gnaisse & SA & MBE & 7 & 6 & 2 & 3,25 & N10 & $55 \mathrm{NE}$ & N.A. \\
\hline 12 & gnaisse & $\mathrm{A}$ & MAE & 2 & 2 & 1,5 & 1,33 & - & - & P.A. \\
\hline 13 & matriz & & & & & & & & & \\
\hline 14 & granulito & SAn & $\mathrm{ME}$ & 50 & 38 & 19 & 2,31 & N150 & $25 \mathrm{SE}$ & P.A. \\
\hline 15 & granulito & SAn & ME & 15 & 12 & 6 & 2,25 & N90 & $35 \mathrm{E}$ & P.A. \\
\hline 16 & granulito & SAn & MAE & 40 & 32 & 27 & 1,33 & N110 & 40SE & N.A. \\
\hline 17 & gnaisse & SA & $\mathrm{MBE}$ & 7 & 7 & 2 & 3,50 & N120 & $10 \mathrm{NW}$ & N.A. \\
\hline 18 & granulito & SA & MAE & 4 & 3 & 3 & 1,16 & N120 & 0 & P.A. \\
\hline 19 & matriz & & & & & & & & & \\
\hline 20 & meta-gabro & SA & $\mathrm{AE}$ & 10 & 5 & 4 & 1,87 & N50 & $40 \mathrm{NE}$ & N.A. \\
\hline 21 & granulito & SAn & $\mathrm{ME}$ & 25 & 12 & 8 & 2,31 & N90 & $20 \mathrm{E}$ & A. \\
\hline 22 & gnaisse & SA & $\mathrm{AE}$ & 22 & 15 & 10 & 1,85 & N120 & 20SE & P.A. \\
\hline 23 & granulito & SA & $\mathrm{AE}$ & 8 & 6 & 4 & 1,75 & N50 & 0 & P.A. \\
\hline 24 & granulito & SA & $\mathrm{BE}$ & 12 & 10 & 4 & 2,75 & N30 & $15 \mathrm{NE}$ & A. \\
\hline 25 & gnaisse & SA & $\mathrm{BE}$ & 7 & 5 & 2 & 3,00 & N120 & $30 \mathrm{SE}$ & A. \\
\hline 30 & matriz & & & & & & & & & \\
\hline 31 & granulito & SAn & $\mathrm{BE}$ & 23 & 15 & 7 & 2,70 & N60 & $30 \mathrm{NE}$ & N.A. \\
\hline 32 & gnaisse & $\mathrm{A}$ & MAE & 5 & 4 & 3 & 1,50 & N90 & $80 \mathrm{~W}$ & A. \\
\hline 33 & granulito & SAn & $\mathrm{BE}$ & 24 & 18 & 14 & 1,50 & $\mathrm{~N} 160$ & $10 \mathrm{SE}$ & P.A. \\
\hline 39 & matriz & & & & & & & & & \\
\hline & & & & & INHA I & & & & & \\
\hline 1 & gnaisse & A & $\mathrm{ME}$ & 25 & 10 & 8 & 2,18 & $\mathrm{~N} 150$ & 20SE & A. \\
\hline 4 & matriz & & & & & & & & & \\
\hline 5 & sieno-granito & An & $\mathrm{AE}$ & 32 & 26 & 18 & 1,61 & N160 & $10 \mathrm{SE}$ & P.a. \\
\hline 9 & lente de arenito & & & & & & & & & \\
\hline 10 & granulito & SAn & $\mathrm{AE}$ & 41 & 26 & 21 & 1,59 & N50 & $50 \mathrm{NE}$ & P.A. \\
\hline 11 & conglomerado fino & & & & & & & & & \\
\hline 12 & granulito & SAn & $\mathrm{AE}$ & 21 & 16 & 12 & 1,54 & N80 & $40 \mathrm{NE}$ & P.A. \\
\hline 13 & pegmatito & An & $\mathrm{MBE}$ & 12 & 7 & 3 & 3,15 & N130 & 20SE & - \\
\hline 14 & lente de folhelho & & & & & & & & & \\
\hline 20 & lente de arenito & & & & & & & & & \\
\hline 25 & lente de folhelho & & & & & & & & & \\
\hline 26 & granulito & San & MAE & 26 & 21 & 16 & 1,47 & N130 & 0 & P.A. \\
\hline 30 & conglomerado fino & & & & & & & & & \\
\hline 31 & granulito & SAn & $\mathrm{AE}$ & 31 & 22 & 17 & 1,55 & N85 & 40SW & P.A. \\
\hline 32 & granulito & SAn & $\mathrm{AE}$ & 7 & 4 & 3 & 1,83 & $\mathrm{~N}-\mathrm{S}$ & 0 & P.A. \\
\hline 33 & conglomerado fino & & & & & & & & & \\
\hline 34 & quartzo & An & $\mathrm{AE}$ & 5 & 3 & 2 & 2,00 & $\mathrm{~N}-\mathrm{S}$ & $70 \mathrm{~N}$ & N.A. \\
\hline 35 & granulito & SA & $\mathrm{BE}$ & 10 & 6 & 3 & 2,66 & N160 & $40 \mathrm{NW}$ & P.A. \\
\hline 36 & conglomerado fino & & & & & & & & & \\
\hline 37 & granulito & SA & $\mathrm{AE}$ & 2 & 1,5 & 1 & 1,75 & $\mathrm{~N} 150$ & $35 \mathrm{NW}$ & N.A. \\
\hline 38 & granulito & SA & $\mathrm{AE}$ & 4 & 3 & 2 & 1,75 & N160 & $40 \mathrm{NW}$ & N.A. \\
\hline 39 & meta-gabro & $\mathrm{A}$ & $\mathrm{ME}$ & 8 & 5 & 3 & 2,16 & $\mathrm{~N} 150$ & 0 & A. \\
\hline 40 & granulito & SA & MAE & 2 & 1 & 1 & 1,50 & N100 & $30 \mathrm{NW}$ & P.A. \\
\hline 41 & conglomerado fino & & & & & & & & & \\
\hline 42 & granulito & SAn & $\mathrm{AE}$ & 8 & 4 & 3 & 2,00 & $\mathrm{~N}-\mathrm{S}$ & 0 & P.A. \\
\hline 43 & granulito & SAn & $\mathrm{AE}$ & 11 & 5 & 4 & 2,00 & N130 & $25 \mathrm{SE}$ & A. \\
\hline 47 & conglomerado fino & & & & & & & & & \\
\hline
\end{tabular}




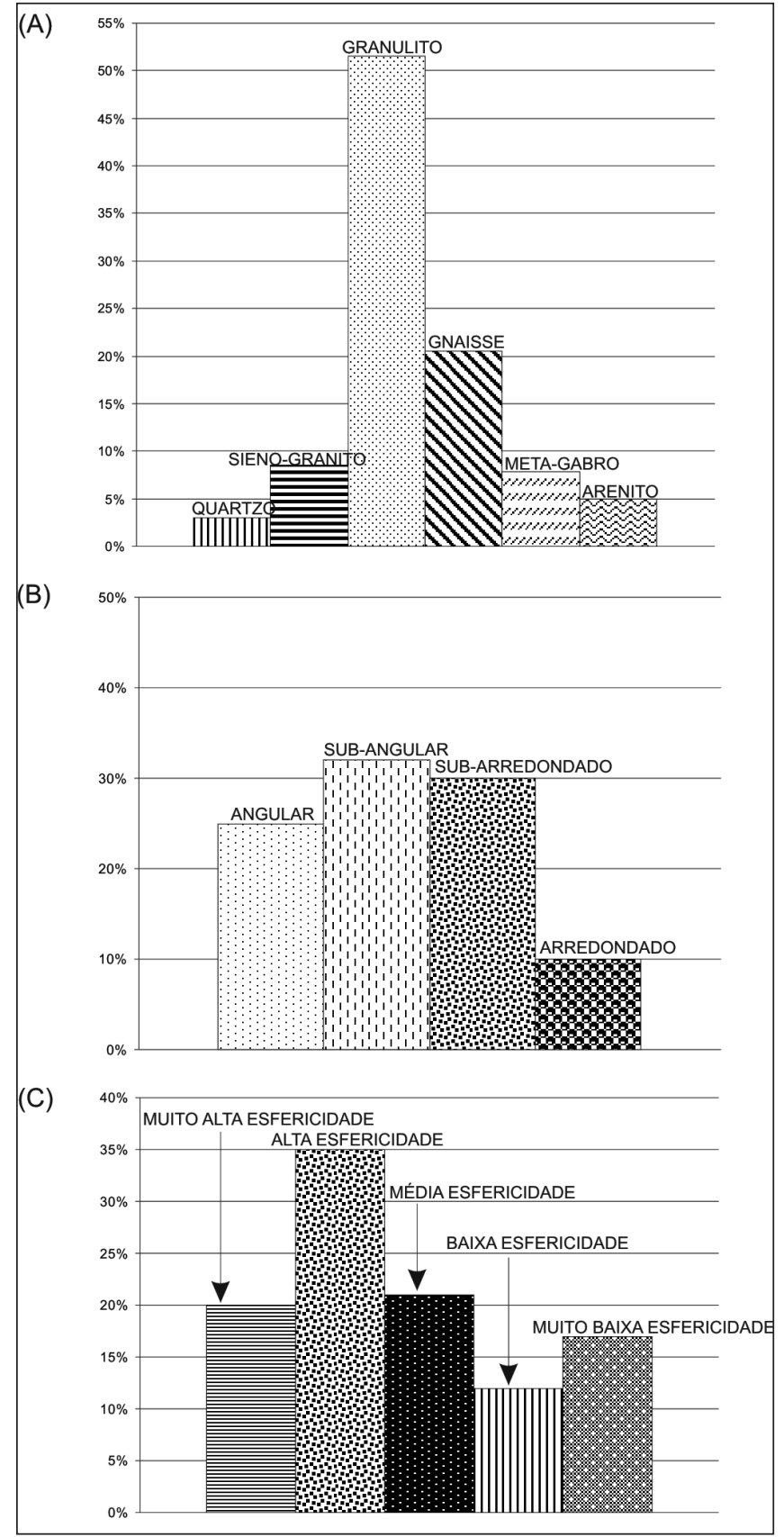

Figura 6-Histogramas de freqüencias para os clastos encontrados no conglomerado de Mont Serrat. (A) Percentagem de presença dos diferentes litotipos; (B) Arredondamento; e (C) Esfericidade.

de que estes foram oriundos de áreas fontes próximas, o que é um aspecto também esperado, diante da proximidade da Falha de Salvador do local do afloramento estudado. A alta esfericidade reflete a natureza da rocha fonte, uma vez que em áreas do embasamento cristalino, na zona de transição solo-rocha inalterada, os blocos de rocha já são relativamente esféricos, antes de serem liberados para transporte.

A composição dos clastos mostra que as rochasfonte foram aquelas do bloco alto da Falha de Salvador formadas por litotipos deformados e metamorfisados arqueano-paleoproterozóicos. Como ocorrem predomi-

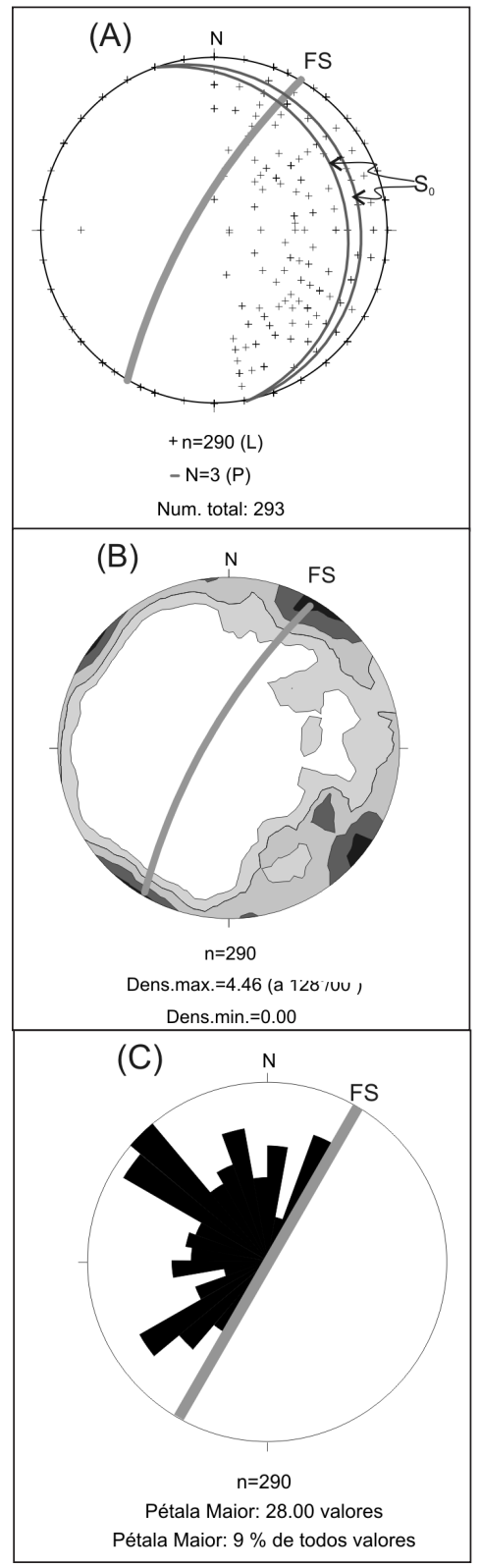

Figura 7 - Plotagem em rede estereográfica igual-área das orientações de 290 eixos maiores de clastos de conglomerado da Formação Salvador em Mont Serrat como linhas (A) e curvas de isodensidade de freqüência $(B)$ e, rosáceas de freqüência de direção, de $10^{\circ}$ em $10^{\circ}(\mathrm{C})$. FS = plano da Falha de Salvador e $S_{0}=$ planos de acamadamento dos pacotes sedimentares, para comparação. Notar a predominância de duas orientações de eixos em relação à $F S$, domínio mais escuro em (B) e pétalas de rosácea em (C): (i) paralelas a sub-paralelas e, (ii) ortogonais a sub-ortogonais. Para maiores detalhes ver o texto. 
nantemente rochas das fácies granulito e anfibolito, é possível deduzir-se que, na época da formação da bacia, as rochas em posições crustais mais rasas provavelmente já haviam sido removidas. Assim, as rochas de alto grau (fácies anfibolito e granulito) foram erodidas e depositadas sob a forma de leques deltaicos, em épocas de enxurradas, no lago tectônico do Recôncavo. Estas foram recorrentes possibilitando o espalhamento dos conglomerados a média distância da borda da bacia interdigitados com os sedimentos finos das formações Candeias e Maracangalha. As camadas de folhelho encontradas dentro dos conglomerados podem ser explicadas pela deposição de material silto-argiloso em pequenos lagos, em épocas calmas, diferentes dos períodos turbulentos das enxurradas que geraram os conglomerados. As lentes de arenito foram contemporâneas à deposição dos conglomerados apresentado contato gradacional com os mesmos.

Quanto à pequena ocorrência de clastos de calcário, trabalhos anteriores (Caixeta et al. 1994) classificam-nos como provenientes da Formação Estância do neoproterozoico, que possivelmente existia nas proximidades da Salvador na época da formação da Bacia do Recôncavo.

$\mathrm{O}$ estudo do afloramento de Mont Serrat, entre os inúmeros existentes na borda das falhas das Bacias do Recôncavo, Tucano Sul/Central, Jatobá e Tucano Norte, constitui apenas uma etapa inicial de um trabalho que pode se expandir, visando um melhor conhecimento do ambiente de deposição dos clastos e a paleogeografia das áreas-fonte que deram origem a esses sedimentos conglomeráticos.

Agradecimentos Ao CNPq pelo financiamento de recursos para a realização dos trabalhos e à CBPMCompanhia Baiana de Pesquisa Mineral pela ajuda nas viagens de campo; ao professor do IGEO/UFBA, Abilio Carlos da Silva Pinto Bittencourt pelas informações com relação à geologia das rochas sedimentares do Grupo Ilhas e aos dois revisores da RBG pelas críticas e sugestões apresentadas. JSFB, JMLD e LCCG agradecem ao CNPq pelas respectivas bolsas de produtividade em pesquisa. Por fim, gostaríamos de deixar aqui consignadas as nossas homenagens à memória do colega $\mathrm{e}$ amigo Jorge Andrade Felizola, já falecido, que iniciou, juntamente com o primeiro autor, os estudos preliminares sobre o conglomerado de Mont Serrat.

\section{Referências}

Caixeta J. M., Bueno V. G., Magnavita L. P., Feijó F. J. 1994. Bacia do Recôncavo, Tucano e Jatobá. Boletim da PETROBRÁS, 8(1):163-172.

Celino J. J., Conceição H., Corrêa-Gomes L.C. 1984. Monzogranito porfirítico: magmatismo ácido tardio no Cinturão Granulítico Atlântico, Salvador, Bahia. In: Congr. Brás. Geol., 33, Rio de Janeiro. Bol. Res., p. 157158.

Corrêa-Gomes L.C. 1992. Diques máficos: uma reflexão teórica sobre o tema e o seu uso prático no entendimento da geodinâmica fissural, Salvador, Bahia. Dissertação de Mestrado, Instituto de Geociências, Universidade Federal da Bahia, 198p.

Corrêa-Gomes L.C., Tanner de Oliveira M.A.F., Cruz M.J.M. Motta A.C. 1996. Província dos Diques Máficos do Estado da Bahia. Texto explicativo, Mapa e Estágio Atual do Conhecimento. SIC/SGM/CBPM/UFBA, Edição Especial, 144 p.

Fujimori S. 1968. Granulitos e charnockitos de Salvador, Bahia. Anais Acad. Brás. Cienc., 40 (2):181-202.

Fujimori S. \& Allard G. O. 1966. Ocorrência de safirina em Salvador, Bahia. Bol. Soc. Brás. Geol. 15(2):67-81.

Magnavita L.P., Sanches C.P. Silva R.R., Hook S.C. 1998. Guidebook to the Reconcavo Rift Basin, Brazil. AAPGABGP International Conference, Rio de Janeiro, Field Trip no 5, 69p.
Medeiros R.A. \& Ponte F.C. 1981. Roteiro Geológico da Bacia do Recôncavo (Bahia). Petróleo Brasileiro S.A. SENPES-DIVEN- Setor de Ensino da Bahia (SEN-BA), $63 \mathrm{p}$.

Mestrinho S.S.P., Linhares P., Carvalho I. G. 1982. Geoquímica de elementos principais e traços do dique de diabásio da praia de Ondina, Salvador, Bahia. In: Congr. Brás. Geol. Salvador, 32, Anais, v.4, p.1862-1877.

Miura K. 1967. Estudo dos fanglomerados na margem leste da Bacia do Recôncavo. Coletânea de Relatórios de Exploração da PETROBRÁS (II), 4:95-110.

Moraes Brito C. 1992. Caracterização geológica, geoquímica e petrológica dos diques máficos proterozoicos da região de Salvador, Bahia. Dissertação de Mestrado, Instituto de Geociências, Universidade de São Paulo, IAG, 96p.

Tanner de Oliveira M. A. F. \& Conceição H. 1982. Metamorfismo de Alto Grau da Faixa Costeira de Salvador, Bahia. In: Congr. Brás. Geol., Salvador, 32, Anais, 2:41-42.

Viana C.F., Gama Jr. E.G., Simões I.A., Moura J.A., Fonseca J.R., Alves R.J. 1971. Revisão estratigráfica da Bacia do Recôncavo-Tucano. Bol. Tec. PETROBRAS, 14(3/4):157192.

Manuscrito A-1528 Aceito em 19 de setembro de 2007 